narrow study of one or more exciting causes into the nervous power that makes their operation possible, and, by viewing it from every angle and from a higher vantage ground, let us hope to hasten the coming of the day when the whole subject shall be lifted out of the dust of controversy and out of the darkness of hypothesis into the light of imperishable fact.

John N. Mackenzie, Baltimore.

\section{THE ADMINISTRATION OF ARSPHENAMIN}

To the Editor:-In your issue of May 10 you publish a letter from the director of the Hygienic Laboratory, U. S. Public Health Service, in which he declares it as a requisite to safe administration of arsphenamin that $0.1 \mathrm{gm}$. of the drug should be dissolved in at least 30 c.c. of fluid and that each injection of $0.3 \mathrm{gm}$. of the drug should require at least six minutes.

While I recognize that it is a wise policy to be overcareful in the administration of such a powerful drug and to err, if at all, on the safe side, I must take issue with the concluding remarks: "any physician who fails to observe these precautions should be considered as directly responsible for serious results that follow the improper use of the drug." As a matter of fact, I can state that in the many thousand injections which have been given in my service at Mount Sinai Hospital, it has been the standard rule to dissolve each $0.1 \mathrm{gm}$. in $20 \mathrm{c.c}$. of freshly distilled water, and to inject it, not with undue haste, but only in exceptional cases where small veins require the use of small needles, as slowly as Dr. McCoy suggests. The average injection takes about half the time defined by him as the minimum.

It is not in the spirit of controversy but with the aim of protecting the medical profession that I ask you to publish this letter, for I realize that if the occurrence of unavoidable reactions, rare as they are, should lead to a suit for malpractice, a well meant but too apodictical statement from such an authoritative source might be detrimental to a member of the profession. H. Goldenberg, M.D., New York.

\section{REPRINTS ON DISORDERS OF THE BLOOD}

To the Editor:-I am setting out to make a collection of reprints and cuttings from the medical press of papers dealing with the clinical and experimental aspects of disorders of the blood. I have already about 2,000 . These are indexed and filed and will, I hope, prove of permanent value.

American literature is not so well represented as I could desire. I have most of the papers on Gaucher's splenomegaly and excerpts from your own pages for the last few years, but much is still lacking. Would you be so good as to print this letter and allow me to ask those interested in the subject to send me any reprints they have.

Accounts of disease chacterized by abnormal shapes of the red cells and by abnormal phagocytosis are practically confined to American literature; there also one looks for much of the work on the spleen and nearly all that on hemolymph glands; purpura is much more fully dealt with than in English literature, and, generally speaking, we have little to compare with your experimental work.

It would be impossible for me to write to each author individually or to keep track of every paper published. Nor can I subscribe to all the journals in which this work is found.

If any reprints of my own are of sufficient interest, I shall of course be delighted to exchange them. Any reprints sent will be acknowledged at once.

I thank you in advance for your courtesy.

GoRDON WARD, M.D.

The Vine, Sevenoaks, Kent, England.

\footnotetext{
A Foresight.-I hope to live to see the time when the increased efficiency in the public health service-federal, state and municipal-will show itself in a greatly reduced death rate. The federal government can give a powerful impulse to this end by creating a model public health service, and making our national capital a model, sanitary city._-President Taft.
}

\section{Queries and Minor Notes}

Anonymous Communications and queries on postal cards will not be noticed. Every letter must contain the writer's name and address, but these will be omitted, on request.

\section{GLUTEN FLOUR FOR DIABETES}

To the Editor:-Will you give me the address of a company which makes gluten flours to be used in the treatment of diabetic patients? Do you consider gluten flour reliable in the treatment of diabetes?

$$
\text { C. T. PANKhurst, M.D., North Star, Mich. }
$$

ANswer.-Gluten flour is not a "treatment" for diabetes in the sense that it has any remedial value. The treatment of diabetes is essentially dietetic and hygienic, drugs playing a minor rôle. An important feature of the dietetic treatment is the restriction of the carbohydrate intake. As the commonest of the carbohydrate-containing foods is bread, the problem of substituting for ordinary bread a product somewhat similar in character, but without so high a starch content, becomes important. Gluten flours have been developed for this purpose. They are essentially wheat flours from which a large proportion of the starch has been removed, leaving a proportionate excess of the protein element (gluten). It thus becomes obvious that the important element in gluten flours is not the presence of larger amounts of protein, but the comparative absence of starch. There are many so-called gluten flours on the market which are extremely dangerous for use in diabetes because of the large proportion of starch they contain. A safe gluten flour is marketed by Herman Barker. Sommerville, Mass. This has been accepted by the Council on Pharmacy and Chemistry for inclusion in New and Nonofficial Remedies. The Barker product comes in three grades: Grade A contains 4 per cent. carbohydrate; Grade B, 7 per cent.; Grade C, 12 per cent. Certain flours for the use of diabetics in making breads, muffins, etc., that are low in carbohydrate content have also been admitted to N. N. R. These, however, do not have wheat flour as their base, and are therefore not gluten flours, the protein element being derived from the soy bean in one case and from milk casein in another.

\section{ABSORPTION OF WATER FROM THE STOMACH}

To the Editor:-I have been taught that water is not absorbed from the stomach. Dr. Casares (The Journal, May 3, 1919, p. 1336) speaks repeatedly to the contrary. Both cannot be right. Is there anything new concerning this question, pro or con?

Evgar A. Hall, M.D., Coal City, Ill.

ANSwer.-The article referred to is on the "Treatment of Malaria" by J. M. Casares y Bescanza, published in Plus Ultra, Madrid, p. 186, and abstracted in THE Journal of May 3. According to most physiologic textbooks, water is not absorbed from the stomach. Fluids pass through the stomach rapidly and are absorbed from the intestine. For years physiologic laboratories have given to medical classes a practical demonstration of this fact. A cat is lightly anesthetized, and 50 c.c. of distilled water heated to $37 \mathrm{C}$. is introduced into the empty stomach, the cardiac orifice of the stomach having previously been ligated off and a ligature placed about the pylorus. A similar amount of water is introduced into the small intestine, both ends of which are closed by ligatures. Care is taken not to interfere with the blood supply to the stomach or intestine. The animal is allowed to recover from the anesthetic and after from three to four hours is again anesthetized. The gastric and intestinal contents are measured, and the stomach is found to contain, on the average, about $47 \mathrm{c} . \mathrm{c}$. of the water introduced -sometimes more, sometimes less; the intestines are invariably empty. Hence, the stomach absorbs practically none of the water, while the intestines absorb all. The slight apparent absorption from the stomach -3 c.c. in three hours - may be accounted for by the adherence of some of the water to the mucous membrane, and this water cannot be recovered. Experiments have shown that absorption of pure distilled water from the stomach is practically nil.

Saline solutions, however, are absorbed from the stomach in appreciable degree when in comparatively high concentration. Howell writes of sodium iodid solution that "Not until its solutions reach: a concentration of 3 per cent. or more does its absorption become important." Experiments have shown that solutions of strychnin are absorbed from a Pawlow's stomach of a dog, precluding the possibility that the solutions were passed into the intestine before absorp- 